\title{
The Role of Energy Return for Energy Invested (EROEI) in Dis- sipative Autocatalytic Systems
}

\author{
Ilaria Perissi ${ }^{1}$, Alessandro Lavacchi ${ }^{2}$ and Ugo Bardi 1 ,* \\ 1 Dipartimento di Chimica, Università degli Studi di Firenze, Via della Lastruccia 3, 50019 Sesto Fiorentino, \\ Italy \\ 2 Consiglio Nazionale delle Ricerche (CNR) - Istituto di Chimica dei Composti OrganoMetallici (ICCOM), \\ Area della Ricerca di Firenze, via Madonna del Piano 10, 50019 Sesto Fiorentino, Italy \\ * Correspondence: ugo.bardi@unifi.it
}

\begin{abstract}
The Energy Return on Energy Invested, EROEI, is known as an important parameter for evaluating the efficiency of energy-producing technologies. In this paper we examine the concept of EROEI from a general viewpoint, giving insights on a wider range of applications. In general, natural resources can be seen as energy stocks characterized by a "potential" that can be exploited by creating intermediate stocks. This transformation is typical of dissipative systems and for the first time we found that Lotka-Volterra model, usually confined to the study of biology of populations, can represent a powerful tool to estimate EROEI for some such systems, providing an understanding of the reason for the overexploitation phenomenon and, in some cases, the collapse of the exploiting system.
\end{abstract}

Keywords: EROEI; Lotka Volterra, dissipative systems; resource exploitation

\section{Introduction}

The energy return for energy invested (EROEI) ${ }^{1},{ }^{2}$ has become a fundamental tool for the evaluation of energy-producing technologies. The EROEI of energy systems is normally calculated by the direct evaluation of the energy flows in real systems, typically making use of life cycle analysis (LCA) techniques ${ }^{2}$. Being based on the ratio of two physical parameters, the EROEI is independent on the vagaries of markets and of consumer preferences, and it can provide, at least in principle, an objective comparison of the performance of energy technologies ${ }^{3}$. Among other things, it provides an immediate filter useful to discard energy technologies whose performance is low (an example is cornbased ethanol ${ }^{4}$ ). Unfortunately, the uncertainties inherent in the calculation or the improper applications of the correct procedures ${ }^{5}$ may lead to different results for the same systems 678,9 .

In the present study, we examine the concept of EROEI from the general viewpoint of the behavior of non-equilibrium systems. This analysis is not supposed to replace the conventional LCA methods, but to provide insight on the role of EROEI in energy technologies and, more in general, on trophic chains.

We use the well-known Lotka-Volterra (LV) model ${ }^{10,}, 11$, a cornerstone in the field of population biology, even though its application to real ecosystems turned out to be problematic ${ }^{12}$. Nevertheless, we will show here how a version of the model that we call the "Single-Cycle Lotka-Volterra" (SCLV) can describe a remarkable variety of real word systems, including fields such as engineering ${ }^{13},{ }^{14}$, social sciences ${ }^{15},{ }^{16}$, business management ${ }^{17}$, decision making ${ }^{18}$, environmental sciences ${ }^{19}$ and more. Our approach sheds light on the phenomenon called "overexploitation," also referred to as "overshoot" ${ }^{20,}{ }^{21}$ which is responsible for the decline or the collapse of complex systems.

\section{Methods}


The first mathematical model describing a dissipative autocatalytic system was independently developed in the 1920 s by Alfred Lotka ${ }^{10}$ and Vito Volterra ${ }^{11}$ and is often referred to as the LV model. It was conceived to describe the interplay between two biological populations at two different trophic levels: one of the two species is defined as the predator and the other the prey. Sometimes, these two levels are referred to as "foxes" and "rabbits."

The model can be seen in a more abstract sense as describing the energy transfer between two energy stocks linked by feedback relationships - it is because of the presence of feedbacks that the system can be defined as "autocatalytic." In this form, the model can describe also non-biological systems. Indeed, its first application to the real world was for an economic system: the fisheries of the Mediterranean sea, in an early work by Volterra himself in collaboration with Roberto D'Ancona ${ }^{22}$. These results were replicated later on other fisheries ${ }^{23}{ }^{24}$. When the model is applied to economic systems, the first stock may be termed "resource" (e.g., an oil field), whereas the second stock is the ensemble of "capital" (equipment, materials, building, workers, etc.) needed to exploit the resource.

The LV model can be described in graphical form using the System Dynamics (SD) conventions ${ }^{25}$. Stocks are represented as rectangles, flows between stocks are represented by double-edged arrows, and the regulation of flows is based on "valves" which may be affected by stocks or by other variables. Single line arrows describe the relations of stocks with flows, highlighting feedback loops.

In the graphical SD view, a two-stock, Lotka-Volterra model can be represented as shown in Figure 1, drawn using the Vensim ${ }^{\mathrm{TM}}$ software package.

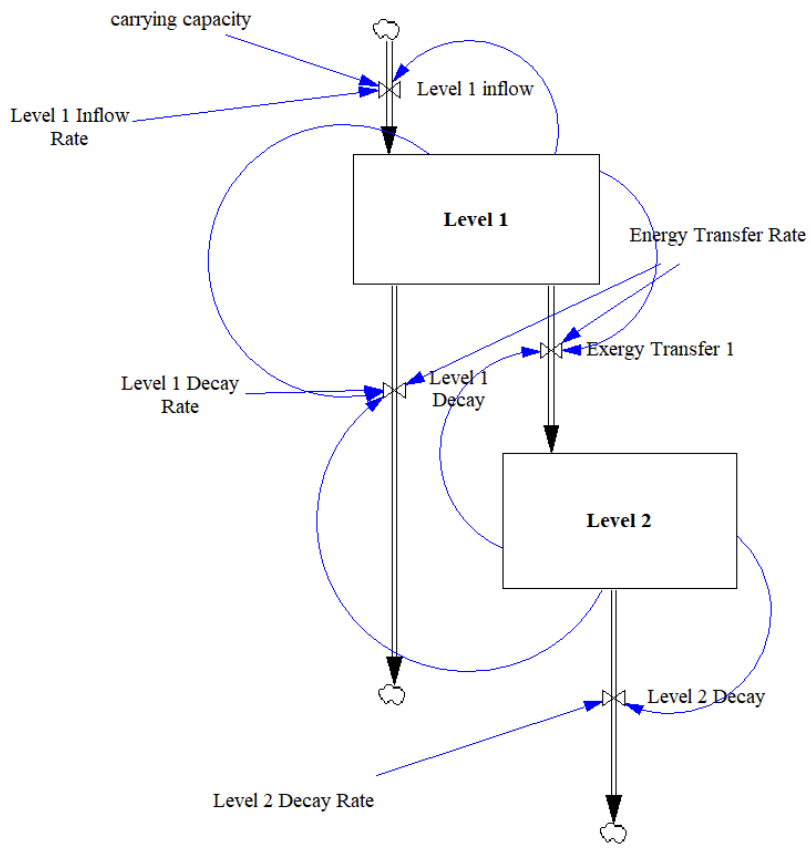

Figure 1 - An interpretation of the 2-stock trophic chain model according to the conventions of System Dynamics.

In this model, we label the two stocks as $L_{1}$ and $L_{2}$. These stocks are normally measured in terms of population, that is number of individuals. But what moves from one stock to the other is not individual rabbits but the metabolic energy they provide to foxes. Therefore, a more general version of the model sees the $L_{1}$ and $L_{2}$ stocks as energy stocks.

We assume that level 1 is at higher potential energy than level 2, so that energy flows from $L_{1}$ to $L_{2}$, but not the reverse (rabbits do not eat foxes, not normally at least). Energy comes into the system from a non-quantified stock (grass) represented as a small cloud in the graphic. This energy accumulates into the L1 stock (rabbits), and it gradually moves to 
the L2 stock (foxes), but some of it is lost to the environment in the form of waste heat. The model is drawn in such a way to emphasize how the flow of energy goes "down" as the potentials are dissipated. It is just a graphical convention, and it doesn't affect the equations of the model.

This graphical representation is useful for an intuitive understanding of the mechanism of the system, but in the following we will mainly use conventional differential equations. The basic equations of the LV model are written below, with $k_{1}, k_{2}, k_{3}$, and $\eta$ as fixed parameters:

$$
\begin{aligned}
& d L_{1} / d t=k_{1} L_{1}-k_{2} L_{1} L_{2} \\
& d L_{2} / d t=\eta k_{2} L_{1} L_{2}-k_{3} L_{2} .
\end{aligned}
$$

As we said earlier on, dimensionally, $L_{1}$ and $L_{2}$ can be both measured in energy units. The $k_{1}$ and $k_{3}$ parameters are measured in units of [time] ${ }^{-1}$, that is as frequency. Their values are proportional to how fast the system replenishes or empties its stocks. $k_{2}$ has the dimension of [time $]^{-1 *}[\text { energy }]^{-1}$ and it is proportional to the rate of interaction of the two stocks. Note that $k_{2}$ as the dimension of the inverse of an "action" (energy*time). It is an attribute of the dynamics of a physical system from which the equations of motion of the system can be derived through the principle of the least action. As recently discussed by Sharma and Annila, the second law of thermodynamics can be understood in terms of an equation of motion ${ }^{26}$. According to Annila, the natural process (energy dissipation in trophic levels) moves following the steepest descents of the potential energy landscape by equalizing differences in energy via various transport, transformation, and dissipative processes e.g. diffusion, heat flows, electric currents and chemical reactions ${ }^{27}$.

In the equations, $\eta$ (eta) is a dimensionless efficiency parameter that can go from zero to one. In many cases, it can be seen as describing the fraction of energy lost as low-temperature heat in the transformation, according to the $2^{\text {nd }}$ law of thermodynamics. Nevertheless, in the case of human-managed systems, a fraction of the flow of energy produced may not be (and usually is not) all reinvested into the capital stock used to produce more energy. Humans tend to use a large fraction of this energy flow in activities that may be defined as "ludic," tourism, politics, football, pyramids, and many more. In the present section, we assume that these factors are incorporated in the $\eta$ factor. The role of the distribution of the energy production in different societal sectors will be discussed later, in the section dedicated to world models.

Although the LV equations are not normally solvable analytically, the time evolution of the $L_{1}$ and $L_{2}$ stocks can be easily determined by numerical methods. In the form written above, the two stocks undergo an unending series of oscillations as a function of time (Figure 2). This behavior makes the LV system an example of a biological clock. It can be shown that it has a frequency equal to $(1 / 2 \pi)\left(k_{1} \eta k_{2}\right)^{1 / 2} 28$.

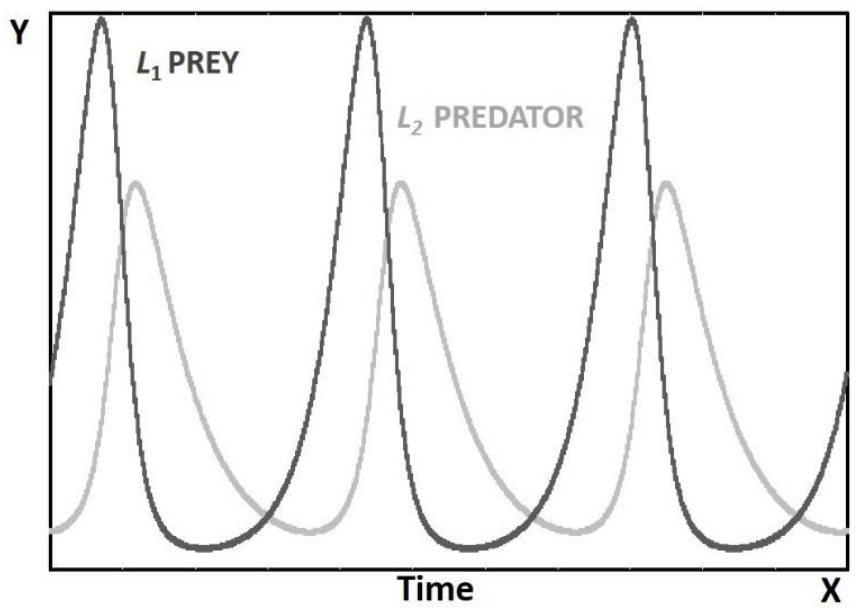


Figure 2 -The result of the simplest version of the Lotka-Volterra 2-stock model

The periodic behavior of the system becomes clearer by looking at a plot of $L_{1}$ and $L_{2}$ in phase space, where the oscillations are represented by a closed trajectory (Figure 3). In this version of the model, all the cycles are identical and superimposable.

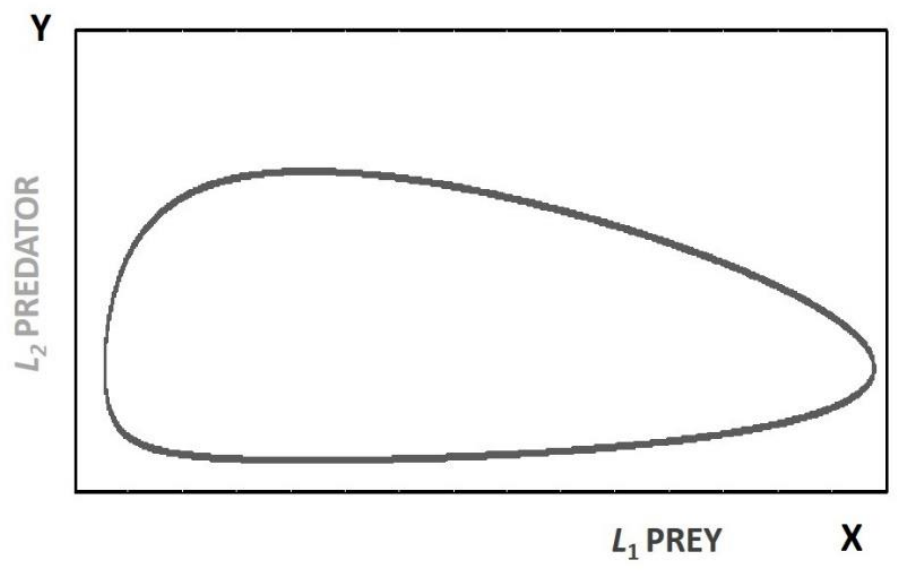

Figure 3 Prey-Predator periodic behaviors represented in the space of the two stocks.

The equations of the basic LV model can be modified in various ways ${ }^{29}$. Perhaps the most common variant is the "competition," or "competitive" model, where the growth of one or both stocks is limited by a parameter called the "carrying capacity" of the system, that is the maximum number of individuals (or their total metabolic energy) that the system can sustain in one or both the stocks considered. Other variants add more parameters and relations, e.g. as predator satiation, visual range, speed, and more ${ }^{30},{ }^{31}$. Most of the alternative models maintain the two-species trophic chain, although it is possible to generalize the model considering " $n$ " trophic levels ${ }^{32}$. These variants are often attractive but always incomplete renditions of the factors that influence the interactions of predators and prey. Despite these added details, the model has described the behavior of just a few real biological populations ${ }^{12}$.

In the present paper, we focus on the simplest form of the Lotka-Volterra model and on the variant we call the SCLV model, where the $k_{1}$ parameter is set to 0 . It means that the higher potential stock is not replenished. This version is not formally different from the standard LV model, since the only constraint for it to describe a physical system is that the constants must not be $<0$. Nevertheless, we use the term SCLV to clearly identify this version in the present paper. SCLV can also be called the "detritivore" LV model since it refers to a condition in which the predator feeds on a non-reproducing or a slowly reproducing prey, as some parasites and predators are known to do. We used this variant to describe such system as the whaling industry which exploits a resource (whales) that reproduces very slowly and whose population was brought to nearly zero during the $19^{\text {th }}$ century exploitation cycle ${ }^{33}, 23$.

These are the equations for the SCLV model:

$$
\begin{aligned}
& d L_{1} / d t=-k_{2} L_{1} L_{2} \\
& d L_{2} / d t=\eta k_{2} L_{1} L_{2}-k_{3} L_{2} .
\end{aligned}
$$

The resulting behavior as a function of time is a single "bell-shaped curve" for both $L_{2}$ stock and for the flow from $L_{1}$ and $L_{2}$. Instead, $L_{1}$ decreases monotonically. Typical results for the SCLV model are shown in figure 4 . Since this model can be used to describe the production cycle of non-renewable economic resources (e.g. crude oil) ${ }^{23}$, as discussed before, the "predator" can be defined as the ensemble of resources used to exploit the resource and therefore it can be labeled as "capital" in order to align the terminology of the model with the commonly used nomenclature in economics. 


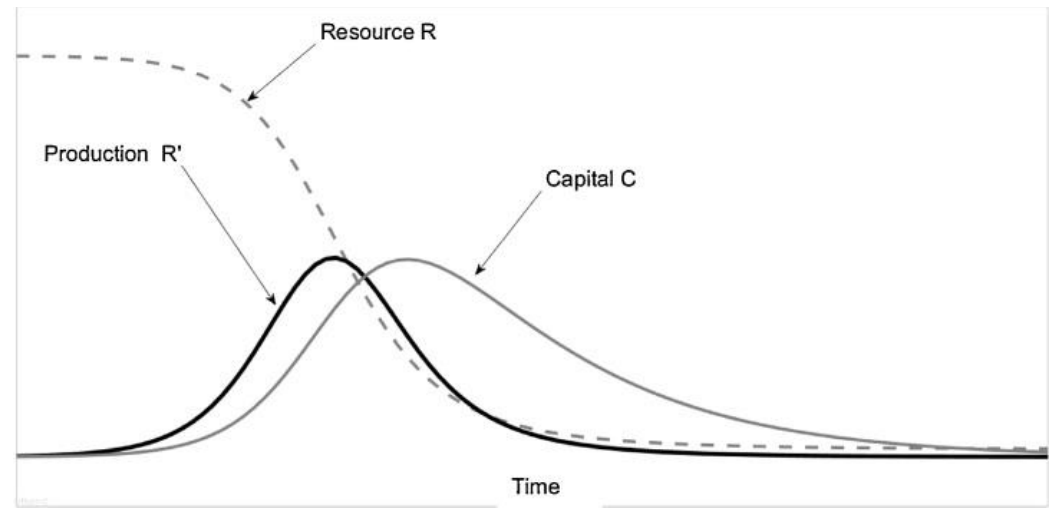

Figure 4-Single-cycle two stock model.

The SCLV model has a stable attractor for $L_{2}=0$ (extinction of the predators), but not necessarily for $L_{1}=0$. In the case of an economic system, it means that the resource will not be completely exploited before the capital stock goes to zero.

In the following, we will maintain the "foxes and rabbits" intuitive image for the stocks even though, of course, rabbits do reproduce. But even when rabbits reproduce "like rabbits," every single cycle of the standard LV model can be qualitatively seen as a case of the SCLV model.

\section{Results}

The LV and SCLV models describe the transfer of energy from a stock to another in a dissipative system. How fast this energy is transferred determines the growth or decline of the whole system. The ratio (Eout)/(Ein) was defined by Charles Hall in 1979 as EROI, or $E R O E I$ (energy return for energy invested) ${ }^{1},{ }^{2}, 343$. More explicitly, it is the energy gained by a stock compared to the energy used by the stock to get it.

The EROEI parameter does not appear in the standard version of the LV equations, but it is the same thing as the "net reproduction rate," a well-known parameter in population biology defined as the ratio of the new individuals being born divided by the number of individuals dead or removed from the population by other factors (e.g., emigration). If we understand a population as a stock of metabolic energy, this definition is equivalent to the $\left(\mathrm{E}_{\text {out }}\right) /\left(\mathrm{E}_{\text {in }}\right)$ ratio.

Since the LV equations describe the evolution of biological populations, the net reproduction rate must be contained in the interplay of the variables and the coefficients. It can be made explicit by rearranging the terms in the equations. For this purpose, note that the "production" of energy can be identified as the flow of energy from the $L_{1}$ (resource) stock into the $L_{2}$ (capital) stock. In the same way, the "expended" energy is the energy that the $L_{2}$ stock loses, that is the flow out of the $L_{2}$ stock

Note that the flow out of the $L_{1}$ stock is not the same thing as the flow into the $L_{2}$ stock. Because of the second law of thermodynamics one unit of energy resource creates much less than one unit of capital energy. The loss for the predator/prey trophic level in vertebrate biological chains is called the "Lindemann efficiency" and it is often estimated as ca. $10 \%$, with a high degree of uncertainty. Recent data ${ }^{35}$ indicate that it can be as low as $1 \%$. This feature is considered in the LV model by means of the $\eta$ parameter which is always $<1$.

Accordingly, in the simple case of a two-level biological trophic chain, the EROEI can be written as the flow of exergy (useful energy) that goes into $L_{2}\left(\eta k_{2} L_{1} L_{2}\right)$ divided the flow of energy out of $L_{2},\left(k_{3} L_{2}\right)$. That is:

$$
E R O E I=\eta k_{2} L_{1} / k_{3}
$$


This term represents the flow of energy turned into capital (gain) divided by the capital lost (loss) in the process. The formula is valid in the same way for the single cycle SCLV model and for the multicycle, standard LV model. However, while in the SCLV model the EROEI declines irreversibly with $L_{1}$, in the multicycle LV model it oscillates periodically. Note that the EROEI is directly proportional to three factors: the efficiency of the transformation, $\eta$, the transformation rate factor, $k_{2}$, and the amount of the resource, $L_{1}$. The EROEI is also inversely proportional to $k_{3}$, the factor that describes how fast capital disappears because of depreciation (definable also as maintenance). The EROEI does not depend on $k_{1}$, as it should not be, because the efficiency of the transformation process is independent on the process that creates new resources. Note also that the $L_{2}$ stock does not appear in the formula. In the LV model, foxes are assumed to chase rabbits at a rate that is independent of their number. Of course, in the real world, economies of scale occur, and some predators do band together to hunt their prey. The formula could be modified making it explicitly proportional to the $L_{2}$. But in the present study we will remain with the basic model assumptions.

Note how this form of the model is highly aggregated with all the capital stock measured using energy as a proxy. We can say that foxes are seen as at the same time energy producers (rabbit hunters) and equipment producers (foxling producers). So, a single stock, L2, describes both activities. But, in many cases, the two activities can be separated, especially in the case of the human economy. For instance, the oil industry is an energy producer, but oil wells do not directly spawn other oil wells. Society dedicates a stock of resources and energy to generate a complete industrial sector that provides the oil industry with materials, equipment, and human power. This differentiation can be accounted for in the model by adding another stock (figure 5).

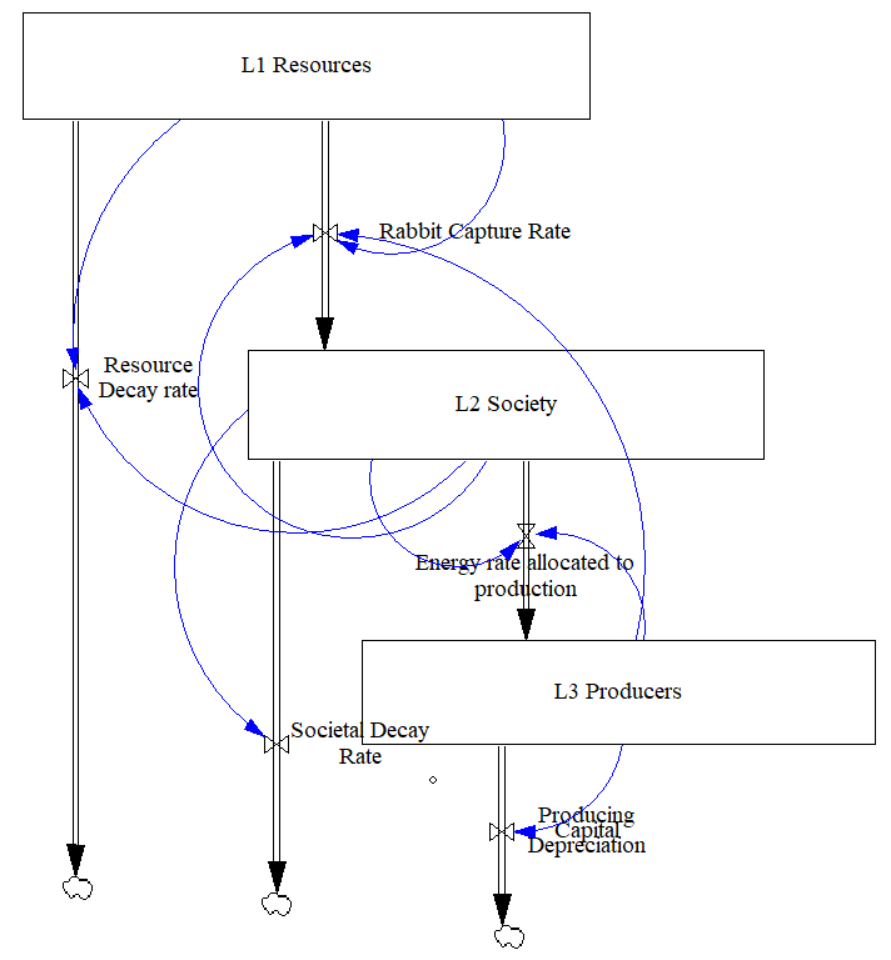

Figure 5 - the disaggregated SCLV described in the text.

This version of the model is the result of a common procedure in system dynamics, where systems can be complexified by adding more stocks and more interactions among them. For instance, the "World3" model used in one of the first dynamic studies of the world system, the Limits to Growth ${ }^{36}$, consisted of 5 main stocks of capital and resources. Other, more recent models include renewable energies ${ }^{37}$ and use larger numbers of 
parameters (see, e.g., the MEDEAS world model ${ }^{38}$ ). In the present case, we aim at keeping the model simple to use it to determine the EROEI in an explicit form. This determination is more difficult to do univocally in a more complex model. Nevertheless, we use this 3stock model as an example to outline how the procedure can be expanded.

In the 3-stock model, the second stock $\left(L_{2}\right)$ stock is "society", the entity that grows on the exploitation of the resources. Note how it grows proportionally to the flow of resources it obtains from the resource stock. At the same time, the societal capital does not directly exploit resources, but it must allocate some capital to the third stock, L3, that aggregates the "producers" - that fraction of the stocks that directly exploits natural resources. It may be thought, for instance as the "oil industry". The resulting three equations are in the SCLV model:

$$
\begin{aligned}
& d L_{1} / d t=-k_{2} L_{1} L_{2} \\
& d L_{2} / d t=\eta_{12} k_{2} L_{1} L_{2} L_{3}-k_{3} L_{2} L_{3} \\
& d L_{3} / d t=\eta_{23} k_{3} L_{2} L_{3}-k_{4} L_{3}
\end{aligned}
$$

Note how production, intended as the flow of energy into the $L_{2}$ stock, is proportional to the producer stock, to the amounts of resources available and to the whole society that provides a market pull for the production. The flow of resources into the producer stock is proportional to the societal stock and to the producer stock itself in terms of compensating capital depreciation.

In this model, the numerator of the EROEI ratio is given by the energy that goes into the $L_{2}$ stock (Societal Stock) which is equal to $\eta_{12} k_{2} L_{1} L_{2} L_{3}$. The denominator is given by the outflow from $L_{2},\left(k_{3} L_{2} L_{3}\right)$. The resulting EROEI is the same as it was defined for the simpler, two-stock system:

$$
E R O E I=\eta k_{2} L_{1} / k_{3}
$$

There are, of course, many possible ways to rearrange the model that could be further itemized by separately considering the various industrial sectors engaged in the task. That would generate different forms for the Eout/Ein ratio. Nevertheless, we believe that this version is the least arbitrary choice. Note that the fraction of energy that goes into the $L_{2}$ stock may be further reduced when some of it is diverted for societal uses into economic systems, but this point will be examined in the section on world models.

Now, remembering the earlier result valid for the standard LV and for the SCLV model: $E R O E I=\eta k_{2} L_{1} / k_{3}$. Therefore $L_{1}=k_{3} E R O E I / \eta k_{2}$. Substituting these values in the LV equations, we have that

$$
\begin{aligned}
& d L_{1} / d t=(1 / \eta) E R O E I\left(k_{1} k_{3} / k_{2}-k_{3} L_{2}\right) \\
& d L_{2} / d t=L_{2} k_{3}(E R O E I-1)
\end{aligned}
$$

Just as for the standard LV system these equations produce oscillations for both stocks. The EROEI parameter oscillates, too, since it is proportional to the $L_{1}$ stock.

In the case of the SCLV model, $k_{1}$ is set to zero and the equations become:

$$
\begin{gathered}
d L_{1} / d t=-(1 / \eta) k_{3} L_{2} E R O E I \\
d L_{2} / d t=L_{2} k_{3}(E R O E I-1)
\end{gathered}
$$

In this version of the model, the $L_{1}$ stock declines monotonically with time since all terms in the first equation are positive. Since the EROEI and $L_{1}$ are directly proportional to each other, also the EROEI will decline monotonically along the production cycle. Neither needs to go to zero but will stabilize in the long run at values $>0$. The second equation shows that the growth of the L2 stock is exponential when we have EROEI $>>1$, which may happen during the initial phases of growth. The $L_{2}$ stock reaches a maximum for EROEI=1, then it declines when EROEI $<1$. The exergy that flows into $L_{2}, \eta k_{2} L_{1} L_{2}$ is conventionally 
termed "production," especially in the case of the oil industry. This quantity can be expressed in terms of the EROEI parameter as EROEI $\left(k_{2} L_{2}-k_{1}\right)$ in the oscillating LV system and as $k_{2} L_{2} E R O E I$ for the SCLV system.

In figure 6 we show the behavior of the EROEI according to the SCLV model. We show also the related parameter known as "Net Energy" which is equal to Eout-Ein and is related to EROEI by the formula: Net Energy $=($ EROEI -1$) \cdot$ Ein. Note that the Net Energy is negative when $\mathrm{EROEI}<1$.

\section{EROEI and NET ENERGY}

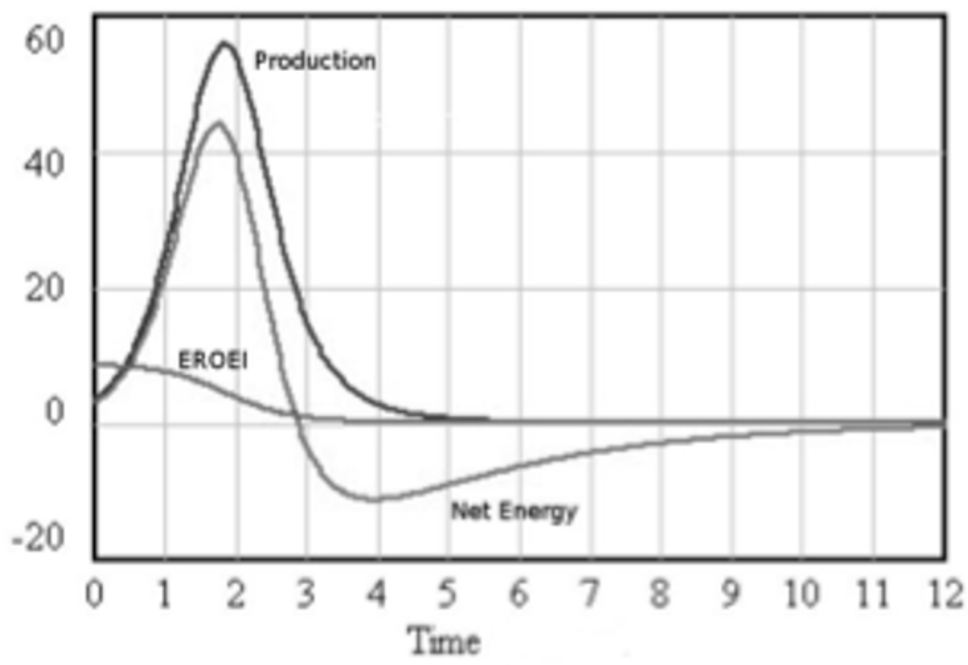

Figure 6. Behavior of the EROEI and of Net Energy according to the SCLV model.

In previous papers ${ }^{33}, 39,40$ we showed that the production curve of a system described by the SCLV model (e.g. oil production) typically follows a "bell-shaped" curve, known as the "Hubbert Curve" in the field of crude oil production ${ }^{41}$. The curve generated by the SCLV model is shown in figure 6. The maximum value of the Hubbert curve is often defined as "Hubbert Peak" or "peak oil," a concept that has generated much interest in the debate about oil depletion ${ }^{42,43}, 44$. It is normally believed that the production curve will be bell-shaped and symmetric, but this is not always the case ${ }^{45} 44$.

The Hubbert curve is often simulated by means of the derivative of a logistic function, but this approach is based on parameters that cannot be directly related to the energy flows - and hence to the EROEI -- of the system. Instead, the SCLV model provides the tools needed to determine the relation of the peak with the EROEI of the system. Taking the second derivative of $d L_{2} / d t$ and setting it to zero for the SCLV case, considering the expression EROEI $=\eta k_{2} L_{1} / k_{3}$, we find that the maximum production occurs when $E R O E I=k_{2} L_{2} / k_{3}+1$. All the terms in this expression are positive, so the production curve will peak and start declining before the EROEI of extraction has become lower than one. In other words, production will peak for an EROEI $>1$.

This is a relevant result relative to the discussion about peak oil, often centered on discussing how dwindling EROEI affects production ${ }^{46}$. Since, as we saw, "peak capital" occurs for EROEI=1, the production curve will peak before the capital curve. This has been observed in studied based on the iterative solution of the LV equations ${ }^{33}, 39,40$.

The determination of the numerical value of the EROEI of a dissipative system could be obtained by fitting the available time-dependent data to the SCLV model, obtaining the model parameters, and calculating the EROEI from the formula EROEI $=\eta k_{2} L_{1} / k_{3}$. The practical feasibility of this method depends on the availability of data expressed in suitable energy units, which is rare. In the present study we are not going into this subject, limiting ourselves to general considerations on the effect of the EROEI parameter on systems that can be described using the LV model. 


\section{Discussion}

The concept of EROEI has been used so far only as a parameter to compare different energy production technologies, for instance renewable energy and fossil energy. In the present section, we provide a discussion of how the EROEI parameter is much more general and it is a characteristic of several real-world systems: biological, economic, and social ones. All these systems are characterized by autocatalytic properties that makes them grow and decline as a function of external perturbations. In most cases, the discussion must remain qualitative since we lack the data that could allow a quantitative determination of the EROEI. Nevertheless, we believe that the EROEI in these systems plays a key role that needs to be understood if we are to face the effects of changes involving such phenomena as the exploitation of natural resources or the growth and decline of civilizations.

\subsection{Biological systems.}

The Lotka-Volterra model is normally described as pertaining to the behavior of biological populations. In practice, in its simplest form, the oscillations that the model produces can be seen in the laboratory for unicellular creatures ${ }^{47}, 48$ but almost never in Nature ${ }^{12}$. It seems that the ecosystem is normally able to maintain homeostatic stability if it is not perturbed by human or other kinds of external perturbations ${ }^{49}$. In these conditions, the flow of energy in and out the stocks of the trophic chains must balance: a biological system in homeostasis must have EROEI=1. An especially interesting case is that of the Earth climate, where the feedbacks among the various stocks generate homeostatic stability ${ }^{50}$, a characteristic that has been termed "Gaia" by Margulis and Lovelock ${ }^{51}$. Gaia, apparently, operates at $\mathrm{EROEI} \approx 1$.

However, cycles of rapid growth and collapse can be observed when the system is strongly perturbed by human activity. We may mention here the case of the reindeer of St. Matthew island ${ }^{52}$ whose population went through a single cycle of growth and collapse, ending in the death of the whole population. Reindeer were introduced by humans, they were not part of the island population, their collapse was due to the overexploitation of the local resources (grass) and the system never reached a stable state with EROEI=1,

\subsection{Epidemics.}

Epidemics are a special case of biological systems where the predator is a pathogen and the prey is a multicellular organism, often human beings. Dynamic epidemiological models were developed in parallel with that of the Lotka-Volterra model, but a few years later, with the "SIR" model (Susceptible, Infectious, Removed) published in $1927{ }^{53}$. The simplest version of the SIR model is equivalent to the SCLV (single cycle) model because the stock of the susceptible people is not replenished $\left(k_{1}=0\right)$. Note also that, in the SIR approach, the efficiency parameter is taken as unity, that is $\eta=1$. That doesn't mean that viruses and bacteria don't obey the laws of thermodynamics, just that in this system this factor can be neglected.

A parameter called $R_{t}$ is often utilized in epidemiology. It is equal to the number of new infections divided by the fraction of infected people. That is, it is the same as the "net reproduction rate" parameter in population biology. The SIR equations show that $R_{t}$ is given by the number of new infections divided by the number of recoveries (or deaths) $\left(k_{3} I\right)$. Determining $R t$ for an ongoing epidemics requires complex procedures ${ }^{54}, 55$ and this necessity often clouds the issue of what $R t$ really is. But, on the basis the definitions given in this paper, $R t$ is conceptually and mathematically the same thing the energy return for energy invested (EROEI), expressed by the same formula, except for the different notation and the lack of the $\eta$ efficiency parameter. An infection spreads for $R_{t}>1$ and declines for $R_{t}<1$. For $R_{t}=1$ the curve of the number of infected cases reaches a maximum which is sometimes defined as the "herd immunity" point. 
A variant of the epidemiologic model deals with the transmission of "memes" in virtual space. The concept of meme was proposed for the first time by Richard Dawkins ${ }^{56}$ as a unit of information that can replicate in the virtual space of human communication (the "memesphere"). Memes tend to "infect" human minds and replicate by a positive feedback (autocatalytic) mechanism. In this case, the meme is described as the predator, whereas the prey is a stock that describes the number of infected human minds. It can be assumed that the infection period is limited in time and that, after a while, people lose interest in the meme, thus becoming immune - nobody dies because of a memetic infection (or, at least, not directly). The result is that memes generate the same curves as for real viruses in real populations. The SCLV model has been successfully used to describe the propagation of memes in virtual space ${ }^{57}$. According to these considerations, it is possible to define an EROEI for meme propagation with the condition that the meme "goes viral" when EROEI $>1$. Unfortunately, we have no data on the actual number of people actually "infected" by a particular meme, only proxy data relative to the number of searches. Nevertheless, the concept of "memetic EROEI" may be a useful mental tool to understand the meme propagation mechanisms.

\subsection{Economic systems.}

In thermodynamic terms, economic systems are not different from biological and physical dissipative systems: in both cases we have trophic chains that irreversibly dissipate thermodynamic potentials. For example, energy production in modern society is mostly based on the dissipation of the chemical potential associated with burning buried hydrocarbons ("fossil fuels"). In this case, the fuel stock is the prey while the extracting industry is the predator. In previous papers ${ }^{33}, 39,40$, we showed how the LV model in the SCLV form can be used to describe this kind of systems, both qualitatively and quantitatively. For the case of oil extraction, the results is a "bell-shaped" curve that agree with the early model for oil extraction proposed in 1956 by Marion King Hubbert 41, a model that was found to account for 38 of 46 oil-producing nations ${ }^{58}$. The SCLV model shows how the "bell-shaped" curve is the unavoidable result of the gradually declining EROEI of extraction, related to the progressive depletion of the less expensive resources.

In this field, much attention has been paid to the concept of "peak oil," the moment when the world's oil production reaches a historical maximum and starts an irreversible decline ${ }^{59}$. From the previous discussion, the SCLV model shows that in an ideal system, the peak is reached at an EROEI $>1$ - it is the capital curve that peaks at EROEI=1. In other words, oil production starts declining when it is still generating useful energy. Most analysis of oil production indicate that, at present, the average current EROEI is still larger than one, but that is not incompatible with the possibility of having reached the production peak in recent times.

The SCLV model could also be successfully applied to the fishing industry, the original subject of Vito Volterra's studies ${ }^{11}$. We were able to show that the model provides a good description of the historical data for the overexploitation of fishing stocks by the fishing industry ${ }^{24}$. Some other examples of the use of the SCLV for the extractive industry are reported in a previous article by Bardi and Lavacchi ${ }^{33}$.

\subsection{Socioeconomic systems.}

The largest existing social systems are called "civilizations" and it has been known for a long time that they follow cycles of growth and decline. A classic example is that of the Roman Empire ${ }^{60}$. Today, the reasons for these cycles are still the object of an extensive debate ${ }^{61},{ }^{62}$. Recently, Bardi et al. proposed a variant of the LV model based on the concept of trophic chain to describe the fall of empires ${ }^{63}$, assuming that civilizations act as predators with respect to natural resources. Even if the resource is potentially renewable, e.g. fertile soil, when it is overexploited, its yield is rapidly reduced, and the result is a decline of the flow of resource into the $L 2$ stock. That leads eventually to decline. 


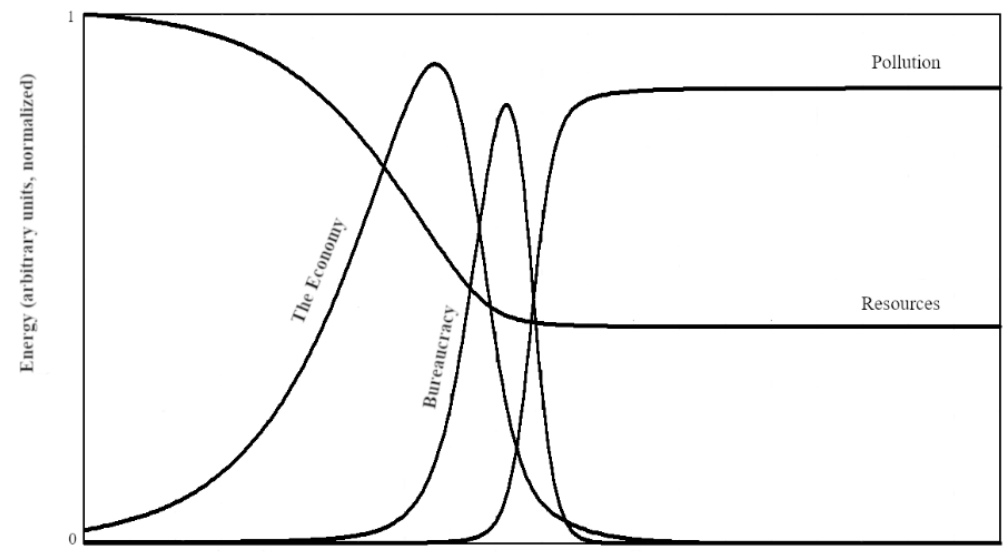

Time

Figure 7 Example of dissipative 3 stocks system: the collapse of a complex society (from Bardi et al. 63

This simple model provides results qualitatively comparable to those of more sophisticated "world models," starting with the pioneering work by Jay Forrester ${ }^{64}$ and of the group of authors who produced the study titled "The Limits to Growth" ${ }^{36}$, a milestone in this area of study.

In this area, Hall et al. ${ }^{65}$ 66, argued that there exists a minimum value of the EROEI that makes it possible the existence of a complex society and estimated that such value was of about 5:1 for society or perhaps 12:1 for a sophisticated modern economy. A large value of EROEI for the specific kind of resource being exploited generates an excess of energy that may be utilized either for the growth of energy production or for other, consumptive purposes. A society that reinvests all the energy it produces into energy production facilities would attain a steady state with EROEI=1:1. That would leave no space for activities that are not directly related to energy production but that we consider important (health care, tourism, art, leisure, sport), although not necessarily worthwhile (war).

We can use the equations developed in the present study to examine this kind of systems. We may consider the fraction of energy diverted to non-productive purpose by multiplying the $\eta$ parameter by a factor written as $\left(1-f_{s}\right)$ where $f_{s}$ stands for "societal factor" and it indicates the fraction of resources that are not re-invested into more resource production. We can call " $f_{s}$ " the "societal disposable income fraction". In this case, we can modify the equations of the single cycle (SCLV) model as:

$$
\begin{aligned}
& d L_{1} / d t=-k_{2} L_{1} L_{2} \\
& d L_{2} / d t=\eta\left(1-f_{s}\right) k_{2} L_{1} L_{2}-k_{3} L_{2} .
\end{aligned}
$$

Remembering that EROEI $=\eta k_{2} L_{1} / k_{3}$

$$
\begin{aligned}
d L_{1} / d t & =-(1 / \eta) k_{3} L_{2} E R O E I \\
d L_{2} / d t & =L_{2} k_{3}\left(\left(1-f_{s}\right) E R O E I-1\right)
\end{aligned}
$$

The $1-f_{s}$ factor does not affect the EROEI of the exploitation of whatever resource a civilization is relying on, but it affects the growth rate of the $L_{2}$ stock $\left(d L_{2} / d t\right)$. If, for instance, $f_{s}$ is equal to 1 , even if the EROEI is much larger than one, all the production is used for building societal capital. In this case, $d L_{2} / d t=0$ and society does not grow. There are historical cases in which a society is believed to have declined as the result of excessive military expenses - that is having dedicated too much of the produced resources to non- 
producing assets. This may have been the case, for instance the Soviet Union in the 1980s 67,68 even though this is unlikely to be the only factor involved.

Provided that $E R O E I>1$, then it is always possible to reduce $f_{s}$ to a value small enough that growth can be maintained or, at least, decline is slowed. In the modern Western society we may be seeing this effect as the result of the depletion of the high EROEI fossil resources ${ }^{66}$. The consequence is that economic growth is maintaining at the expense of downsizing or the elimination of services such as universal health care, state pensions, public schools, and more. Fossil fuels allowed the production of many more goods and services by requiring only 20 percent (1850, coal) or even 10 percent or less of all economic activity to be required to run the rest of the economy ${ }^{65}, 63$. Alternatively, for example in England in 1500, about half of all economic activity was to get the energy (food, fodder, wood) to run society, with much less left over for amenities ${ }^{69}$. A similar phenomenon may have taken place for the decline of the Roman Empire, generated by the progressive depletion of the mineral resources it was dependent upon ${ }^{70}$.

These considerations provide guidelines for understanding the deep reasons of the decline of many societies in history. Unfortunately, the definition of an " $f_{s}$ " factor is frayed with uncertainties. For instance, we might say that the large budget allocated to military expenses in the US is an example of an unnecessary burden on society. On the other hand, it might be argued that, according to the so-called "Carter Doctrine" ${ }^{11}$, without such expenses the US could not access the production of fossil resources in regions such as the Middle East. In such an interpretation, a large fraction of the US military budget should be factored in the calculation of the EROEI of fossil fuels, which would be consequently reduced, perhaps well below unity. That does not detract from the general observation that a declining EROEI may be the main factor involved in civilization decline or collapse.

\section{Conclusions}

The focus of our study was on the role of the Energy Return for Energy Invested $(E R O E I)^{2}$ in irreversible autocatalytic systems where the dissipation of energy potentials occur. Many of these systems can be described by a simple model, the well-known LotkaVolterra (LV) one ${ }^{10}, 11$. In the form we call here single-cycle Lotka-Volterra (SCLV), the model turned out to be a powerful tool to evaluate the efficiency in resource use in several different fields.

We highlighted how the diminishing EROEI typical of non-renewable (or slowly renewable resources) provides a qualitative understanding of the decline and collapse of economic and social systems. It also provides an understanding of how a society that feels the crunch of reduced available energy tends to react by cutting on societal segments felt to be not indispensable, such as universal health care or other state-managed public services.

The SCLV model coupled with the concept of EROEI, provides a window of understanding on the "overexploitation" trap in the way many natural and human-made systems work. Moreover SCLV model allowed to unveil some mathematical and conceptual equivalence of the $R_{t}$ parameter in epidemiologic studies to the energy return on energy invested (EROI or EROEI) parameter in the biophysical approach to energy economics ${ }^{72}$, that, to our knowledge, had not been pointed out in the scientific literature before.

Supplementary Materials: This paper involves no supplementary materials.

Author Contributions: Conceptualization, U.B., A.L. and I.P.; methodology, A.L. and U.B.; software, I.P.; validation, U.B., A.L. and I.P.; formal analysis, I.P.; writing-original draft preparation, U.B. and I.P.; writing - review and editing, U.B. and I.P.; supervision, U.B.

Funding: This research received no external funding.

Acknowledgments: The authors are grateful to Professor Charles Hall for his comments and criticism of the manuscript.

Conflicts of Interest: “The authors declare no conflict of interest." 


\section{References}

1. Hall, C. A. S., Lavine, M. \& Sloane, J. Efficiency of energy delivery systems: Part I. An economic and energy analysis. Environment Mgment 3, 493-504 (1979).

2. Gupta, A. K., Hall, C. A. S. C., Gupta, A. K. \& Hall, C. A. S. C. A Review of the Past and Current State of EROI Data. Sustainability 3, 1796-1809 (2011).

3. Hall, C. A. S., Lambert, J. G. \& Balogh, S. B. EROI of different fuels and the implications for society. Energy Policy 64, $141-152$ (2014).

4. Murphy, D. J., Hall, C. A. S. \& Powers, B. New perspectives on the energy return on (energy) investment (EROI) of corn ethanol. Environ Dev Sustain 13, 179-202 (2011).

5. Hall, C. A. S. The History, Future, and Implications of EROI for Society. in Energy Return on Investment: A Unifying Principle for Biology, Economics, and Sustainability (ed. Hall, C. A. S.) 145-169 (Springer International Publishing, 2017). doi:10.1007/978-3-319-47821-0_12.

6. Ferroni, F. \& Hopkirk, R. J. Energy Return on Energy Invested (ERoEI) for photovoltaic solar systems in regions of moderate insolation. Energy Policy 94, 336-344 (2016).

7. Raugei, M. et al. Energy Return on Energy Invested (ERoEI) for photovoltaic solar systems in regions of moderate insolation: A comprehensive response. Energy Policy 102, (2017).

8. Carbajales-Dale, M., Raugei, M., Fthenakis, V. \& Barnhart, C. Energy Return on Investment (EROI) of Solar PV: An Attempt at Reconciliation [Point of View]. Proceedings of the IEEE 103, 995-999 (2015).

9. Hall, C. A. S., Dale, B. E. \& Pimentel, D. Seeking to Understand the Reasons for Different Energy Return on Investment (EROI) Estimates for Biofuels. Sustainability 3, 2413-2432 (2011).

10.Lotka, A.J. Elements of Physical Biology. Williams and Wilkins Company (Williams and Wilkins Company, 1925). doi:10.2105/AJPH.15.9.812-b.

11. Volterra, V. Fluctuations in the abundance of a species considered mathematically. Nature 118, 558-560 (1926).

12.Hall, C. A. S. An assessment of several of the historically most influential theoretical models used in ecology and of the data provided in their support. Ecological Modelling 43, 5-31 (1988).

13.Wiener, N. Cybernetics: or, Control and communication in the animal and the machine. (The MIT Press, 2019).

14.Åström, K. J. \& Murray, R. M. Feedback systems: an introduction for scientists and engineers. (Princeton University Press, 2021). 
15. Bowen, M. G. Feedback thought in social science and systems theory, George P. Richardson Philadelphia: University of Pennsylvania Press, 1991. System Dynamics Review 8, 105-107 (1992).

16.Wolstenholme, E. \& McKelvie, D. Feedback Dynamics. in The Dynamics of Care 89-105 (Springer International Publishing, 2019). doi:10.1007/978-3-030-21878-2_5.

17.Simon, H. A. On the Application of Servomechanism Theory in the Study of Production Control-A Study in the Theory of Organization. (RAND Corporation, 1951).

18.Forrester, J. W. Industrial Dynamics: A Major Breakthrough for Decision Makers. Harv. Bus. Rev. 36, 37-66 (1958).

19.Wang, X. \& Fu, F. Eco-evolutionary dynamics with environmental feedback: Cooperation in a changing world. EPL 132, $10001(2020)$.

20.Catton, W. Overshoot, the ecological basis of revolutionary change. (Illinin Books Edition, 1982).

21.Perissi, I. \& Bardi, U. The Sixth Law of Stupidity: A Biophysical Interpretation of Carlo Cipolla's Stupidity Laws. Systems 9, 57 (2021).

22.D’Ancona, U. La Lotta Per l'Esistenza. (Giulio Einaudi Editore, 1942).

23.Perissi, I., Bardi, U., Bardi, U. \& El Asmar, T. Dynamic patterns of overexploitation in fisheries. Ecological Modelling 359, (2017).

24.Bardi, U. \& Perissi, I. The Empty Sea. What Future for the Blue Economy? (Springer, 2020).

25.Bruckmann, G. Elements of the system dynamics method. Technological Forecasting and Social Change 21, 85-87 (1982).

26.Sharma, V. \& Annila, A. Natural process--natural selection. Biophysical chemistry 127, 123-8 (2007).

27.Dilip, K. \& Ilya, P. Modern Thermodynamics. (John Wiley \& Sons, 1998).

28.Demirel, Y. Chapter 13 - Nonequilibrium thermodynamics approaches. in Nonequilibrium Thermodynamics (ed. Demirel, Y.) 356-372 (Elsevier Science, 2002). doi:10.1016/B978-044450886-7/50013-8.

29.Tyutyunov, Y. \& Titova, L. From Lotka-Volterra to Arditi-Ginzburg: 90 Years of Evolving Trophic Functions // Biology Bulletin Reviews. 10, 167-185 (2020).

30.Arditi, R. \& Ginzburg, L. R. Coupling in predator-prey dynamics: Ratio-Dependence. Journal of Theoretical Biology 139, 311-326 (1989).

31.Clark, W. C., Jones, D. D. \& Holling, C. S. Lessons for ecological policy design: A case study of ecosystem management. Ecological Modelling 7, 1-53 (1979).

32. Michaelian, K. Thermodynamic stability of ecosystems. Journal of theoretical biology 237, 323-35 (2006). 
33. Bardi, U. \& Lavacchi, A. A Simple Interpretation of Hubbert's Model of Resource Exploitation. Energies 2, 646-661 (2009).

34.Hall, C. A., Cleveland, C. J. \& Kaufmann, R. Energy and Resource Quality: The Ecology of the Economic Process. (Wiley Interscience, 1986).

35.McIntosh, A. R. et al. Capacity to support predators scales with habitat size. Science Advances 4, eaap7523 (2018).

36. Meadows, D. H., Meadows, D. L., Randers, J. \& Bherens III, W. The Limits to Growth. (Universe Books, 1972).

37.Perissi, I. Highlighting the archetypes of sustainability management by means of simple dynamics models. Journal of Simulation 0, 1-14 (2019).

38.N/a. The MEDEAS project. www.medeas.com (2016).

39. Bardi, U., Lavacchi, A. \& Yaxley, L. Modelling EROEI and net energy in the exploitation of non renewable resources. Ecological Modelling 223, 54-58 (2011).

40.Perissi, I., Bardi, U., El Asmar, T. \& Lavacchi, A. Dynamic patterns of overexploitation in fisheries. Ecological Modelling 359, (2017).

41.Hubbert, M. K. Nuclear Energy and the Fossil Fuels. in Spring Meeting of the Southern District, American Petroleum Institute, Plaza Hotel, San Antonio, Texas, March 7-8-9, (1956).

42.Murphy, D. D. J. \& Hall, C. A. S. C. Energy return on investment, peak oil, and the end of economic growth. Annals of the New York Academy of Sciences 1219, 52-72 (2011).

43.Bardi, U. No peak oil yet? The limits of the Hubbert model. The Oil Drum http://www.theoildrum.com/node/7241 (2011).

44.Bardi, U. Peak Oil. in nternational Encyclopedia of Social and Behavioral Sciences 2nd Edition (Elsevier, 2013).

45.Brandt, A. R. Testing Hubbert. Energy Policy 35, 3074-3088 (2007).

46.Heun, M. \& Wit, M. de. Energy return on (energy) invested (EROI), oil prices, and energy transitions. Energy Policy (2012).

47.Gause, G. F. Experimental Studies on the Struggle for Existence: I. Mixed Population of Two Species of Yeast. J. Exp. Biol. 9, 389-402 (1932).

48.Gause, G. F. Experimental demonstration of Volterra's periodic oscillations in the numbers of animals. Journal of Experimental Biology 12, 44-48 (1935).

49.Gorshkov, V. G., Makar'eva, A. Mikhaĭlovna. \& Gorshkov, V. V. Biotic regulation of the environment: key issue of global change. (Springer-Verlag, 2000). 
50.Berner, R. A. The long-term carbon cycle, fossil fuels and atmospheric composition. Nature 426, 323-6 (2003).

51.Lovelock, J. E. \& Margulis, L. Atmospheric homeostasis by and for the biosphere: the gaia hypothesis. Tellus 26, 210 (1974).

52.Klein, D. R. The Introduction, Increase, and Crash of Reindeer on St. Matthew Island. Journal of Wildlife Management 32, 350-367 (1968).

53.Kermack, W. O., McKendrick, A. G. \& Walker, G. T. A contribution to the mathematical theory of epidemics. Proceedings of the Royal Society of London. Series A, Containing Papers of a Mathematical and Physical Character 115, 700721 (1927).

54.Brauer, F. \& Castillo-Chavez, C. Continuous Population Models. in Mathematical Models in Population Biology and Epidemiology (eds. Brauer, F. \& Castillo-Chavez, C.) 3-47 (Springer, 2012). doi:10.1007/978-1-4614-1686-9_1.

55.Saltelli, A. et al. Five ways to ensure that models serve society: a manifesto. Nature 582, 482-484 (2020).

56. Dawkins, R. The Selfish Gene. (Oxford University Press, 1976).

57.Perissi, I., Falsini, S. \& Bardi, U. Mechanisms of meme propagation in the mediasphere: a system dynamics model. Kybernetes IN PRESS, (2018).

58.Hallock, J. L., Wu, W., Hall, C. A. S. \& Jefferson, M. Forecasting the limits to the availability and diversity of global conventional oil supply: Validation. Energy 64, 130-153 (2014).

59.Campbell, C. J. \& Laherrere, J. F. The End of Cheap Oil. Scientific American 80-86 (1998).

60.Gibbon, E. History of the Decline and Fall of the Roman Empire. (Strahan \& Cadell, 1776).

61. Tainter, Joseph, A. The collapse of complex societies. (Cambridge University Press, 1988).

62.Tainter, Joseph, A. Complexity, Problem Solving, and Sustainable Societies. in Getting Down to Earth - Practical Applications of Ecological Economics (Island Press, 1996).

63. Bardi, U., Falsini, S. \& Perissi, I. Toward a General Theory of Societal Collapse. A Biophysical Examination of Tainter s Model of the Diminishing Returns of Complexity. (2018).

64.Forrester, J. World dynamics. (Wright-Allen Press, 1971).

65.Hall, C., Balogh, S. \& Murphy, D. What is the minimum EROI that a sustainable society must have? Energies 2, 2547 (2009).

66.Lambert, J. G., Hall, C. A. S., Balogh, S., Gupta, A. \& Arnold, M. Energy, EROI and quality of life. Energy Policy 64, 153-167 (2014).

67. Reynolds, D. B. Cold War Energy: The Rise and Fall of the Soviet Union. (Alaska Chena LLC, 2016). 
68. Reynolds, D. \& Kolodziej, M. Former Soviet Union oil production and GDP decline: Granger causality and the multicycle Hubbert curve. Energy Economics (2008).

69.King, C. W., Maxwell, J. P. \& Donovan, A. Comparing World Economic and Net Energy Metrics, Part 1: Single Technology and Commodity Perspective. Energies 8, 12949-12974 (2015).

70.Bardi, U. The Seneca Effect. Why Growth Is Slow but Collapse Is Rapid. (Springer Verlag, 2017).

71.Klare, M. Protecting Overseas Oil Supplies: The Globalization of the "Carter Doctrine". in Transforming Power (Routledge, 2006).

72.Hall, C., Lindenberger, D. \& Kümmel, R. The Need to Reintegrate the Natural Sciences with Economics: Neoclassical economics, the dominant form of economics today, has at least three fundamental flaws. BioScience (2001). 